\title{
Prevention of Carbody Vibration of Railway Vehicles Induced by Imbalanced Wheelsets with Displacement-Dependent Rubber Bush*
}

\author{
Takahiro TOMIOKA**, Tadao TAKIGAMI**, Atsushi FUKUYAMA*** and \\ Takashi SUZUKI ${ }^{* * *}$ \\ ** Vehicle Noise and Vibration Lab., Railway Technical Research Institute, \\ 2-8-38 Hikari-cho, Kokubunji-shi, Tokyo, 185-8540, Japan \\ E-mail: tomioka@rtri.or.jp \\ *** Industrial Anti-Vibration Engineering Department, Tokai Rubber Industries, LTd., \\ 1 Higashi 3-chome, Komaki-shi, Aichi, 485-8550, Japan
}

\begin{abstract}
This paper discusses the issue of carbody excitation of railway vehicles due to rotation of imbalanced wheelsets and proposes a simple and cost-effective countermeasure. The basic mechanisms of the carbody excitation are first described, then a displacementdependent rubber bush, which is used for the connection between bogie frame and carbody, is proposed. The displacement-dependent property is realized by introducing a small gap between the rubber and the inner fixture, and the transmission of excitation force with high-frequency and small displacement are isolated by the gap. The small gap can be created naturally just by skipping the bonding process of rubber and inner fixture, so it is very simple and cost-effective countermeasure against this issue. The stiffness property can be tailored to meet the requirements from motional properties of the bogie by applying a Finite Element Analysis (FEA). The effectiveness and validity of the displacement-dependent rubber bushes applied for traction links are investigated and confirmed by both numerical calculation and excitation test using a full-scale test vehicle in the rolling stock testing plant.
\end{abstract}

Key words : Railway, Comfortability in Riding, Forced Vibration, Vibration Isolation, Bending Vibration, Imbalanced Wheel, Displacement-Dependent Rubber Bush

\section{Introduction}

The mass imbalance, or simply imbalance, of wheelset(s) of railway vehicles sometimes increases during service operation. The carbody vibration induced by rotation of imbalanced wheelsets may cause a significant issue in terms of ride comfort. When an imbalanced wheelset rotates, the vehicle is excited with the frequency of the rotation of the wheelset. If the excitation frequency corresponds to one of the natural frequencies of elastic vibrations of the carbody, the carbody vibration intensely increase and impair the ride comfort. This issue may emerge among the vehicles running at the speed of around $80-130 \mathrm{~km} / \mathrm{h}$.

This topic has been recognized for a long time in operation and maintenance fields of railway. Despite the fact, numerous pertinent literatures are unavailable, and majority of them is merely consisting of a report of measurement test or theoretical studies ${ }^{(1)-(5)}$. In this paper, the authors deal with the issue including description of a measurement results for an actual vehicle with imbalanced wheelsets running on a real track, theoretical study of excitation mechanisms and proposal of a countermeasure based on them, investigation of the proposed countermeasure by some numerical studies, and experimental validation using a full-scale vehicle.

${ }^{*}$ Received 5 Nov., 2009 (No. 09-0679) [DOI: 10.1299/jmtl.3.131]

Copyright (c) 2010 by JSME 


\section{Excitation of Carbody Due to Imbalance Mass of Wheelsets}

\subsection{Excitation Mechanism}

The upper limit of mass imbalance in a wheel as-manufactured is regulated as $0.25 \mathrm{~kg} \mathrm{~m}$ in Japan ${ }^{(4),(5)}\left(0.05 \mathrm{~kg} \mathrm{~m}\right.$ for Shinkansen vehicles $\left.{ }^{(5)}\right)$. Nevertheless, the mass imbalance sometimes becomes larger than the limit during service operation. The reason is not completely clear; more than one reason is presumable for the growth of mass imbalance, however, one possible cause may be small misalignment during wheel turning (see Appendix).

When an imbalanced wheelset rotates, generated centrifugal force excites bogie frame in every direction in the plane of wheel rotation. Since the wheelset rolls on rails, only the longitudinal component should be taken into account as the excitation force to the vehicle. The longitudinal force varies sinusoidal with respect to time, and its frequency $f_{\text {ib }}$ is expressed as

$$
f_{\text {ib }}=V /(3.6 \pi D),
$$

where $f_{\mathrm{ib}}[\mathrm{Hz}]$ is the excitation frequency, $V[\mathrm{~km} / \mathrm{h}]$ is the velocity of the vehicle and $D[\mathrm{~m}]$ is the diameter of the wheel. Figure 1 shows the velocity-excitation frequency relation for $D=0.86$ and $0.80 \mathrm{~m}$.

According to the experimental studies for existing railway vehicles by the authors ${ }^{(6)-(8)}$, several complicated vibration shapes (such as differing vibration patterns in the roof and the floor) are observed among commuter-type vehicles. Figure 2 shows an example of measured vibration mode shapes of a commuter-type test vehicle. As shown here, the natural frequencies of major carbody bending vibration modes exist relatively narrow frequency range, usually 8

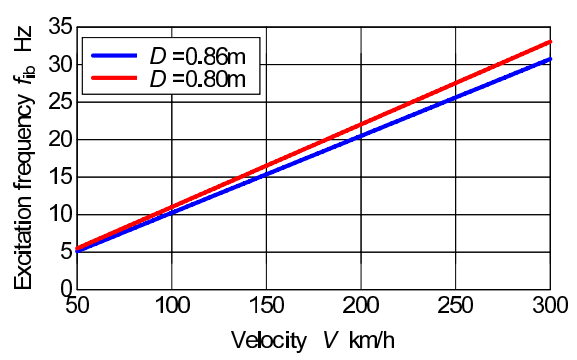

Fig. 1 Relationship between running velocity and excitation frequency due to imbalanced wheel.

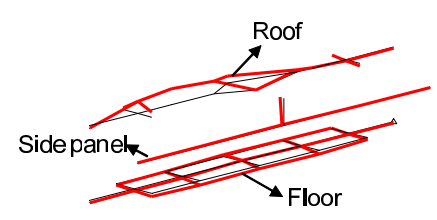

(a) $8.27 \mathrm{~Hz}$

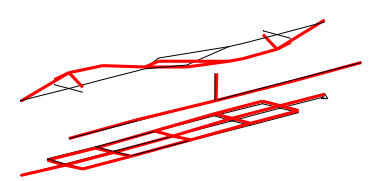

(c) $9.28 \mathrm{~Hz}$

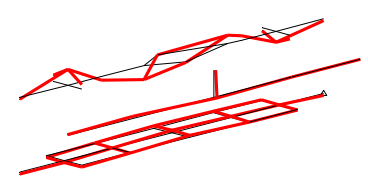

(e) $14.47 \mathrm{~Hz}$

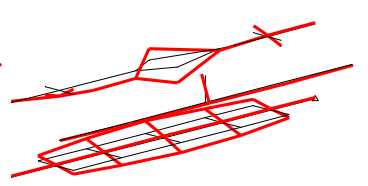

(b) $8.28 \mathrm{~Hz}$

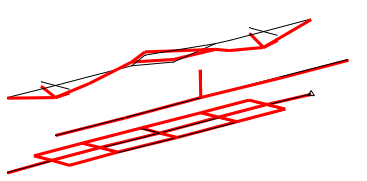

(d) $10.64 \mathrm{~Hz}$

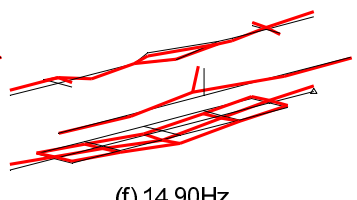

(f) $14.90 \mathrm{~Hz}$

Fig. 2 Examples of mode shapes and natural frequencies measured with a commutertype test vehicle. 


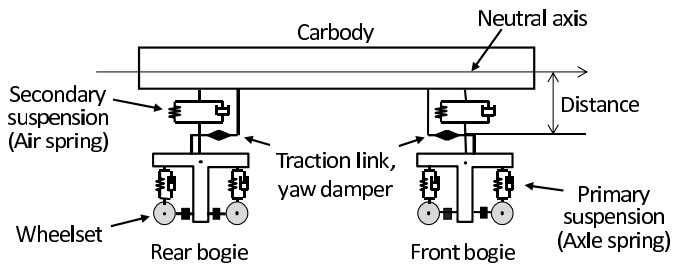

(a) Schematic illustration of railway vehicle.

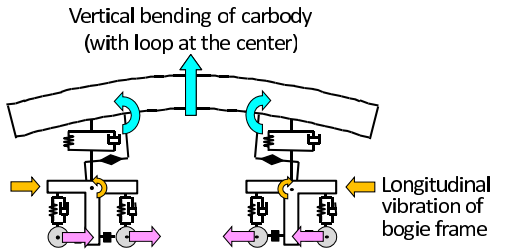

(b) Counter-phase longitudinal vibration of both bogies. (Imbalance phase: $0 \mathrm{deg}$. in each bogie, 180 deg. between bogies.)
Longitudinal and vertical bending of carbody

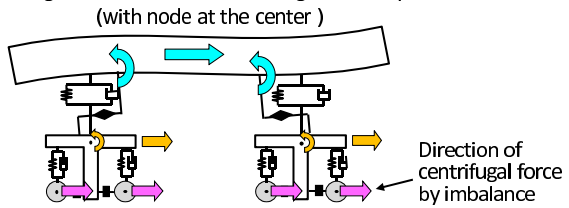

(c) In-phase longitudinal vibration of both bogies. (Phase of all imbalances are $0 \mathrm{deg}$. among all wheelsets.)

Fig. 3 Coupling of carbody vertical bending and bogie longitudinal motion.

to $15 \mathrm{~Hz}$, and such vibrations affect ride comfort. We can see from Fig. 1 that the excitation frequency corresponding to common operational running velocity prevailing in Japan (except Shinkansen), i.e. between 80 to $130 \mathrm{~km} / \mathrm{h}$, overlaps the range of the natural frequencies of carbody bending vibrations of commuter-type vehicles.

The longitudinal excitation force generated by the rotation of imbalanced wheel causes a bogie frame longitudinal vibration. As shown in Fig. 3, the bogie frames and the carbody are connected in the longitudinal direction with traction links and yaw dampers. Since there are distances between the neutral axis of the carbody bending and positions (heights) of traction links and yaw dampers, the longitudinal motion of the bogie frame generates a bending moment on the carbody. This yields carbody vertical bending vibration.

When the excitation frequency $f_{\mathrm{ib}}$ coincides with one of the natural frequencies of the carbody bending vibrations, the bending vibration becomes large and this worsens ride comfort on the vehicle. It should be noted that the excitation of carbody vertical bending vibration depends upon the vibration phase between front and rear bogies; if both bogies vibrate in the counter-phase, such bending vibrations with loop at the center of carbody are mainly excited (Fig.3(b)); on the other hand, both bogies' in-plane longitudinal vibration induce mainly those bending vibrations with node at the center of carbody and carbody longitudinal vibration as shown in Fig 3(c). Since minor differences exist among wheels, such as variation in diameter and/or slip etc., the vibration phase between both bogies varies with time even if the vehicle runs at a constant velocity. This means the excitation moment upon a vertical bending vibration also varies with time while running.

\subsection{Running Test Result for a Commuter-Type Vehicle}

Figure 4 shows an example of acceleration power spectral density (PSD) measured at the center of floor of a commuter-type vehicle during a running test on an existing track ${ }^{(9)}$. Figures 4 (a) and (b) express the results when the same vehicle ran on different sections. The black and green lines respectively show the cases that the vehicle was equipped with small and large imbalanced wheelsets. The running velocity was approximately $95 \mathrm{~km} / \mathrm{h}$ for all cases. In the Fig.4 (a), a prominent peak is observable around $10.5 \mathrm{~Hz}$, which corresponds to the rotational frequency of the vehicle's wheelsets, on the green line. Since no prominent peak is visible on the black line and the PSDs changed almost in the same manner for the other frequency, the prominent peak in the green line is caused by the imbalance of wheelsets. 


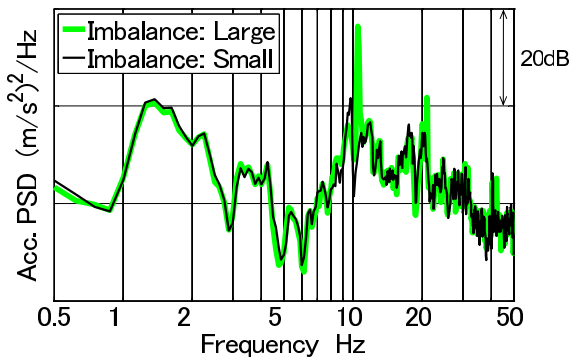

(a) In running section $\mathrm{A}$.

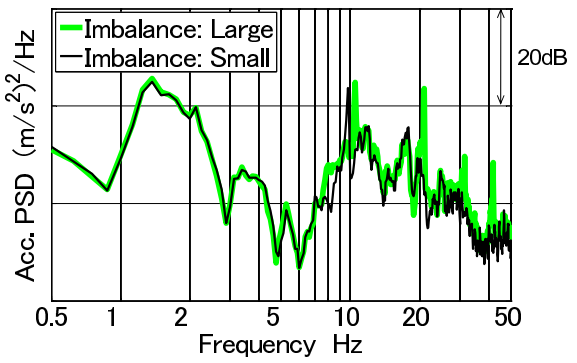

(b) In running section $\mathrm{B}$.

Fig. 4 Vertical acceleration PSD of a commuter-type vehicle measured at the center of the floor during a running test. $(V \approx 95 \mathrm{~km} / \mathrm{h})$

On the other hand, the difference between the large and small imbalance cases is unclear in Fig.4 (b). It can be found from these results that the magnitude of the carbody vibration varies even if the imbalance and velocity is unchanged. This may be a proof of the above mentioned excitation mechanism; that is, a phase change between both bogies.

\subsection{Countermeasure Policy}

The fundamental countermeasure to suppress the excitation by the imbalanced wheelsets is naturally to reduce the imbalance of the wheelsets itself. However, it is difficult to maintain the imbalance sufficiently small by a means of cost; therefore, it is needed to suppress carbody excitation even if some amount of imbalance would exist. The following two countermeasures are considered for instance:

(1) Vibration isolation at the connection of bogie and carbody.

( 2 ) Keeping the phase relation of imbalance (i.e. direction of centrifugal forces) between wheelsets not to excite the carbody bending vibration.

With respect to the (2) above, although it is realizable by introducing some control devices in traction and braking system, it is somewhat an unrealistic idea at present time. We therefore employ the (1) in this study.

As mentioned above, the excitation force generated by the rotation of imbalanced wheelset is transmitted from a bogie frame to a carbody through traction links and yaw dampers. Rubber bushes are commonly used at the connection of these devices to the bogie frame and the carbody. If the stiffness of these rubber bushes is sufficiently low, the transmission of excitation force can be suppressed. It is, however, not practical to reduce the stiffness of rubber bushes greatly from the viewpoint of the original functions of these devices.

In general, the bogie motions accompanied with power running, braking and yawing, are supposed to be static or with low frequency up to $5 \mathrm{~Hz}$ at the highest, and the transmitted force and deformation of rubber bushes with these motions may become large. On the other hand, the longitudinal bogie vibration to excite carbody bending has a frequency higher than $5 \mathrm{~Hz}$, and the transmitted force and rubber bush deformation are supposed to be not so large. Considering these differences, both of original function and proper vibration isolation will be balanced if the rubber bush has a large stiffness sufficiently when subjected to a low frequency and a large force (large displacement), and a small stiffness under a higher frequency and small force (small displacement).

The authors herewith propose a displacement-dependent rubber bush, which has property that the stiffness becomes large for a large displacement and vice versa. We carried out a numerical study as described in the next Chapter to indicate the basic availability of the concept, and then, built experimental pieces of the rubber bush, and investigated the effectiveness using an existing commuter-type test vehicle. 


\section{Numerical Study}

\subsection{Calculation Model}

Figure 5 shows a vibration-analysis model of a railway vehicle used here ${ }^{(4),(10),(11)}$. The vertical deformation of carbody is modeled as a simple Bernoulli-Euler beam as supported by two bogies with air springs. The longitudinal motion of the carbody is also taken into account. The bogies are modeled as a combination of rigid body elements; with vertical, longitudinal and pitching motions of bogie frames and vertical and longitudinal motion of wheelsets.

The excitation forces are input into the wheelsets as a form of centrifugal force as

$$
P_{\mathrm{e}}=m_{\mathrm{w}} \varepsilon(2 V / 3.6 D)^{2},
$$

where $m_{\mathrm{w}}[\mathrm{kg}]$ is the mass of a wheelset, $\varepsilon[\mathrm{m}]$ is an equivalent eccentricity of the wheelset and $D[\mathrm{~m}]$ is the diameter of the wheel.

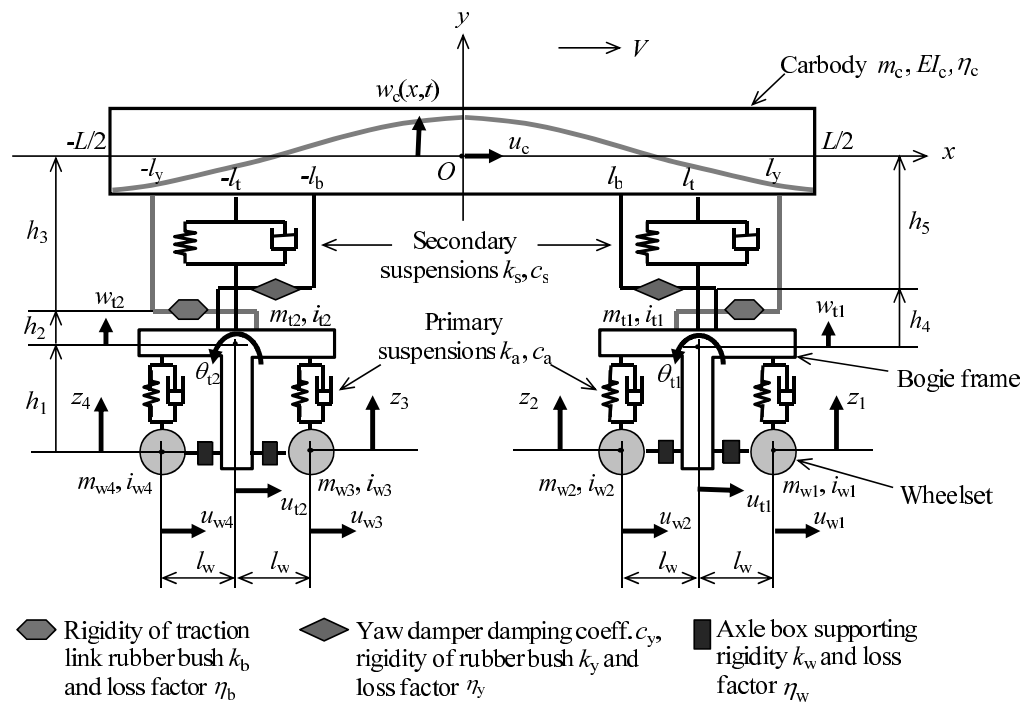

Fig. 5 Schematic view of the railway vehicle analytical model.

\subsection{Calculation Results}

Using the vehicle analytical model, response accelerations at the center of the carbody in vertical and longitudinal direction versus excitation force generated by imbalance of a wheelset were calculated. In this calculation, $m_{\mathrm{w}} \varepsilon=1 \mathrm{~kg} \mathrm{~m}$ was employed as imbalance and the centrifugal force generated by the imbalance was input into only \#1 wheelset. This condition represents the worst case that the limit value of imbalance for a wheel in Japan $\left(0.25 \mathrm{~kg} \mathrm{~m}^{(4),(5)}\right)$ exists in all wheelsets, and both types of carbody vibration as shown in Fig.3 (b) and (c) can be excited by the imbalance.

The specification parameters used for the calculations are listed in Table 1. They represents a commuter-type test vehicle described in Chapter 5. Since a steady state response characteristics of carbody is discussed qualitatively here, the rubber bush stiffness was modeled as frequency-dependent in place of displacement-dependent for simplification. Figure 6 illustrates the frequency-dependent property of rubber bush stiffness used for traction link. The vertical scale of the figure shows the stiffness ratio $K_{\mathrm{d}} / K_{\mathrm{S}}$ where $K_{\mathrm{d}}$ and $K_{\mathrm{S}}$ are the dynamic and static stiffness of rubber bush, respectively. Note that this vehicle had no yaw dampers.

The calculated vertical and longitudinal accelerations at the center of carbody versus excitation frequency $f_{\mathrm{ib}}$ are shown in Fig.7 (a) and (b), respectively. The green and black lines express the cases that normal and frequency-dependent rubber bushes were used, respectively. It is observable that the accelerations higher than $5 \mathrm{~Hz}$ are generally reduced for both of vertical and longitudinal direction when the frequency-dependent rubber bush was applied. This 
Table 1 Specification parameters of a commuter-type vehicle.

\begin{tabular}{|c|c|c|c|}
\hline \multicolumn{3}{|c|}{ Parameter } & Value \\
\hline \multirow{3}{*}{ Carbody } & Length & 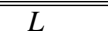 & $19.5 \mathrm{~m}$ \\
\hline & Mass & $m_{\mathrm{c}}$ & $10.6 \times 10^{3} \mathrm{~kg}$ \\
\hline & Bending rigidity & $E I_{\mathrm{c}}$ & $6.83 \times 10^{8} \mathrm{Nm}^{2}$ \\
\hline \multirow{2}{*}{ Bogie frame $(m=1,2)$} & Mass & $m_{\mathrm{t} m}$ & $1.4 \times 10^{3} \mathrm{~kg}$ \\
\hline & $\begin{array}{l}\text { Radius of gyration of } \\
\text { pitching motion }\end{array}$ & $i_{\mathrm{t} m}$ & $0.6 \mathrm{~m}$ \\
\hline \multirow{2}{*}{ Secondary suspension } & Rigidity & $k_{\mathrm{s}}$ & $2.0 \times 10^{6} \mathrm{~N} / \mathrm{m} /$ bogie \\
\hline & Damping coeff. & $c_{\mathrm{s}}$ & $6.6 \times 10^{4} \mathrm{Ns} / \mathrm{m} /$ bogie \\
\hline \multicolumn{2}{|c|}{ Distance between bogie centers } & $2 l_{\mathrm{t}}$ & $13.8 \mathrm{~m}$ \\
\hline \multicolumn{2}{|c|}{ Wheel base } & $2 l_{\mathrm{w}}$ & $2.5 \mathrm{~m}$ \\
\hline \multirow{2}{*}{ Wheel $(n=1, \ldots, 4)$} & Mass & $m_{\mathrm{w} n}$ & $1.24 \times 10^{3} \mathrm{~kg}$ \\
\hline & $\begin{array}{l}\text { Radius of gyration along } \\
\text { with wheel axle }\end{array}$ & $i_{\mathrm{w} n}$ & $0.3 \mathrm{~m}$ \\
\hline \multirow{2}{*}{ Primary suspension } & Rigidity & $k_{\mathrm{a}}$ & $3.0 \times 10^{6} \mathrm{~N} / \mathrm{m} / \mathrm{axle}$ \\
\hline & Damping coefficient & $c_{\mathrm{a}}$ & $2.0 \times 10^{3} \mathrm{Ns} / \mathrm{m} / \mathrm{axle}$ \\
\hline \multicolumn{2}{|c|}{ Axle box supporting rigidity } & $k_{\mathrm{W}}$ & $7.7 \times 10^{6} \mathrm{~N} / \mathrm{m} /$ box \\
\hline \multicolumn{3}{|c|}{ Traction link rubber bush static stiffness } & $4.5 \times 10^{6} \mathrm{~N} / \mathrm{m} / \mathrm{link}$ \\
\hline
\end{tabular}

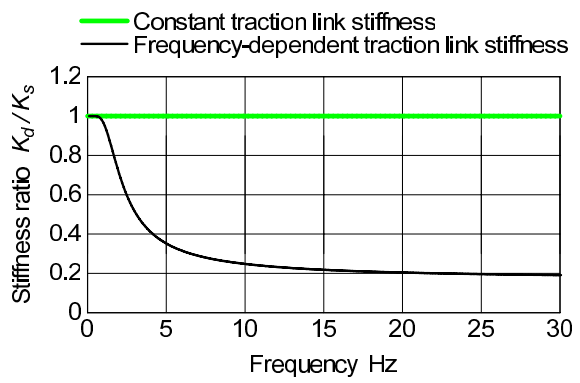

Fig. 6 Frequency-dependent property of traction link rubber bush stiffness used for the numerical calculation.

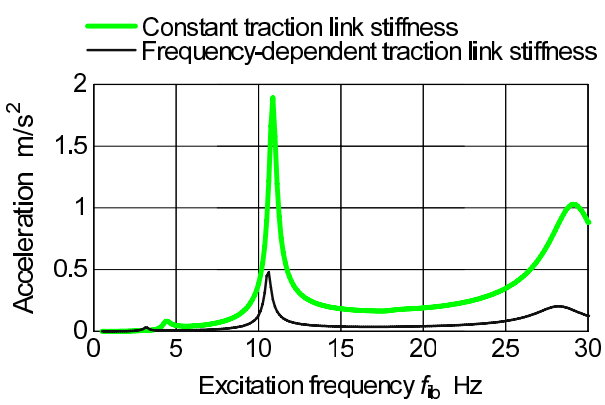

(a) Vertical acceleration

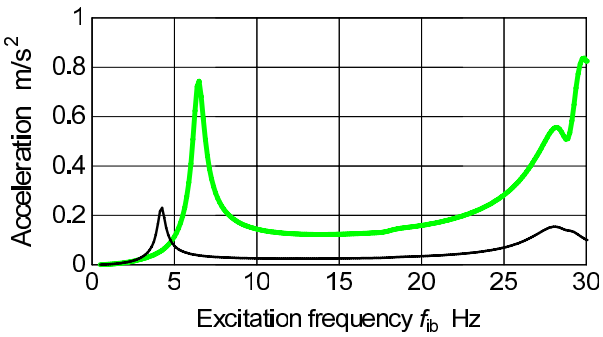

(b) Longitudinal acceleration.

Fig. 7 Calculated acceleration at the center of the carbody. (Response acceleration at the center of carbody. Imbalance $m_{\mathrm{w}} \varepsilon=1 \mathrm{~kg} \mathrm{~m}$ was applied in the \#1 wheelset.)

result may indicate the displacement-dependent rubber bush is also effective to suppress the carbody excitation due to imbalanced wheelset.

\section{Development of the Displacement-Dependent Rubber Bush}

\subsection{Basic Configuration}

To realize the displacement-dependent stiffness property, the authors developed a rubber bush that has a small gap between rubber and inner fixture. The inner fixture is used to fix the traction link to bogie frame or carbody. Note that an ordinary (or normal) rubber bush has no such a gap; the rubber is bonded with the inner fixture strictly in normal rubber bushes. The gap can be created naturally just skipping bonding process of rubber and inner fixture. 
When the relative displacement between bogie frame and carbody is smaller than the gap, the stiffness of the rubber bush is much smaller than the stiffness of the rubber itself. This yields a displacement-dependent property of the rubber bush stiffness.

\subsection{Designing Rubber Bush Properties Using FEA and Unit Test Results with Trial Pieces}

In general, rubber bush stiffness of a traction link (and also of a yaw damper) is determined by considering motional properties of a bogie, such as running stability. Therefore, the static stiffness must be designed to meet those requirements. For ordinary rubber bushes, the stiffness is controllable by adjusting the composition of additives. However, such an ordinary method is inapplicable for the newly developing rubber bush.

In this study a Finite Element Analysis (FEA) considering contraction of rubber during production process was introduced to design the stiffness of the rubber bush. Two different rubber bushes with static stiffness $K_{\mathrm{s}}=9.0 \times 10^{6} \mathrm{~N} / \mathrm{m}$ (Type A) and $12.0 \times 10^{6} \mathrm{~N} / \mathrm{m}$ (Type B) were designed by using the FEA and eight experimental pieces were manufactured, respectively. Figure 8 shows a comparison of deformation-stiffness relation between the FEA results and representative examples of the measured data. It can be found that the FEA results are consistent with measured data, and the validity of the FEA to design the rubber bush stiffness property has been clearly shown.

We measured the static and dynamic stiffness according to the JIS E4710 ${ }^{(12)}$. Table 2 shows the unit test results on the stiffness. In this study, a target value of the dynamic stiffness $K_{\mathrm{d}}$ was set as $0.2 K_{\mathrm{s}}$ or below. The dynamic stiffness $K_{\mathrm{d}}$ was defined as the maximal value obtained when swept sinusoidal deformation with a constant amplitude of $\pm 0.5 \mathrm{~mm}$ from 3 to $50 \mathrm{~Hz}$ were applied between rubber bush inner fixture and outer casing. It is apparent that the dynamic stiffness was sufficiently smaller than the static stiffness. In the mean time, the variances of these stiffness values were relatively large.

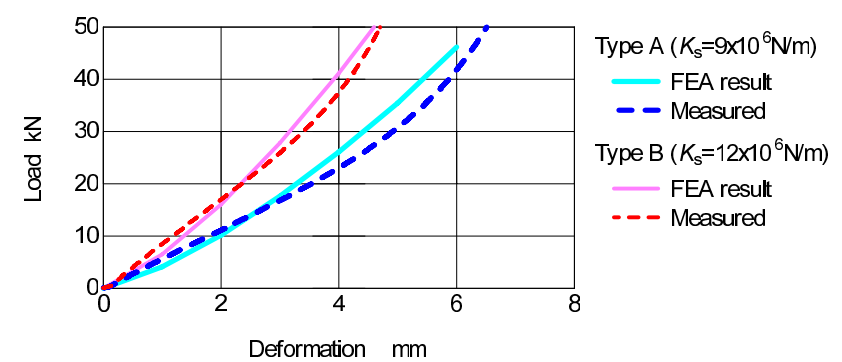

Fig. 8 Comparison of deformation-load relation of the displacement-dependent rubber bush.

Table 2 Unit test results of the displacement-dependent rubber bushes*.

\begin{tabular}{c|ccc}
\hline Type & $\begin{array}{c}\text { Static stiffness } K_{\mathrm{s}} \\
\times 10^{6} \mathrm{~N} / \mathrm{m}\end{array}$ & $\begin{array}{c}\text { Dynamic stiffness } K_{\mathrm{d}} \\
\times 10^{6} \mathrm{~N} / \mathrm{m}\end{array}$ & $\begin{array}{c}\text { Stiffness ratio } \\
K_{\mathrm{d}} / K_{\mathrm{s}}\end{array}$ \\
\hline A & $9.37(0.23)$ & $0.72(0.13)$ & $0.076(0.013)$ \\
\hline B & $12.1(0.33)$ & $0.80(0.29)$ & $0.066(0.023)$ \\
\hline *Average value (Standard deviation); $N=8$. &
\end{tabular}

\section{Validation Test Using a Full-Scale Test Vehicle}

\subsection{Excitation Test in the Rolling Stock Testing Plant}

A series of excitation and vibration measurement test was carried out at the rolling stock testing plant in the Railway Technical Research Institute (RTRI). The testing plant has eight driving rollers, and the cross sectional shapes of the rollers are almost identical to those of rails. By setting a whole vehicle on the rollers and by rotating them, running condition of the vehicle can be simulated. If imbalances are introduced in some of the wheelsets, the vehicle is excited at the same frequency of the rotation of imbalanced wheelset(s). 


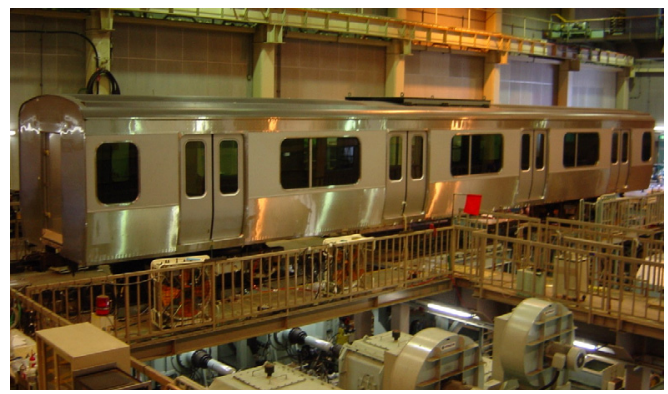

Fig. 9 The test vehicle in the rolling stock testing plant.

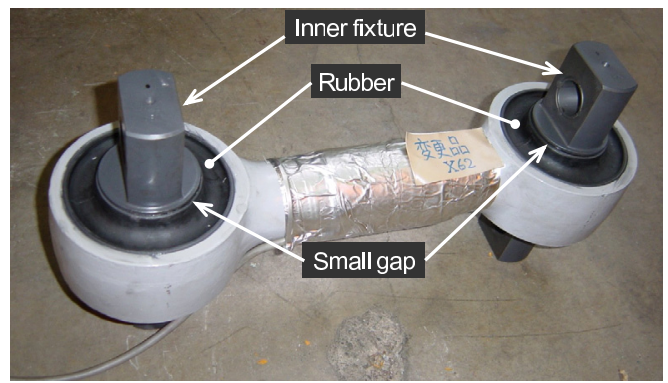

Fig. 10 The traction link equipped with displacement-dependent rubber bushes.

Figure 9 shows a photograph of the measurement test. The vehicle to be tested was a test vehicle owned by the RTRI. It has almost identical carbody structures, with stainless steel carbody shell, to those in the current commuter-type vehicles in Japan. The traction link equipped with the displacement-dependent rubber bushes is shown in Fig.10.

\subsection{Development of Variable-Imbalance Wheelsets}

To recreate the excitation by the imbalanced wheelset while running of an existing vehicle, the authors also developed the variable-imbalance wheelsets. These wheelsets have 48 bolt-holes on the outer rim of each wheel as shown in Fig.11, and imbalance can be varied from about 0 to $0.5 \mathrm{~kg} \mathrm{~m}$ by changing the position and the length of the bolts. Two sets of variable-imbalance wheelsets were built and installed as \#1 and \#4 wheelsets of the tested vehicle. Prior to the excitation test at the rolling stock testing plant, the dynamic imbalance measurement tests were carried out for both of the variable-imbalance and normal wheelsets.

\subsection{Excitation Test Results}

We carried out excitation tests by setting the imbalance as shown in Table 3. The rotation velocity of the driving rollers were adjusted to $124 \mathrm{~km} / \mathrm{h}\left(f_{\mathrm{ib}}=13.2 \mathrm{~Hz}\right)$, and acceleration of the carbody and the bogies were measured during 20 min for each test. The velocity was

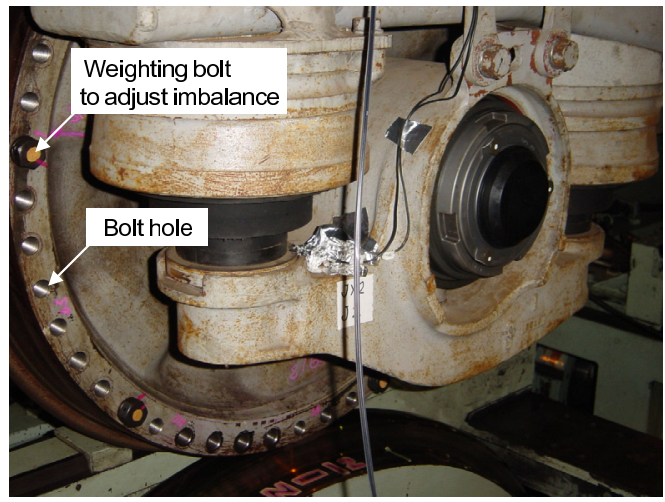

Fig. 11 The variable-imbalance wheelset. 
Table 3 Imbalance conditions for the excitation test.

\begin{tabular}{cc|c|c|c}
\hline $\begin{array}{c}\text { Wheelset } \\
\text { number }\end{array}$ & \multirow{2}{*}{ Type of wheelset } & Diameter of & \multicolumn{3}{|c}{ Imbalance kg m } \\
& & wheel* $D$ m & Small & Large \\
\hline$\# 1$ & Variable-imbalance & 0.8304 & 0.033 & 0.540 \\
\hline$\# 2$ & Normal & 0.8307 & \multicolumn{3}{|c}{0.134} \\
\hline$\# 3$ & 0.8309 & \multicolumn{3}{|c}{0.126} \\
\hline \multicolumn{2}{c|}{ Normal } & 0.8306 & 0.013 & 0.527 \\
\hline \multicolumn{2}{c}{ *ariable-imbalance } & Average value of both side wheels
\end{tabular}

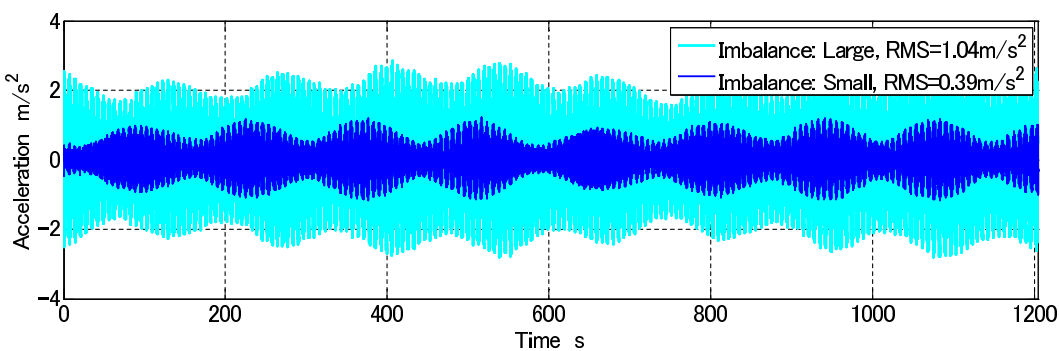

(a) Vertical acceleration.

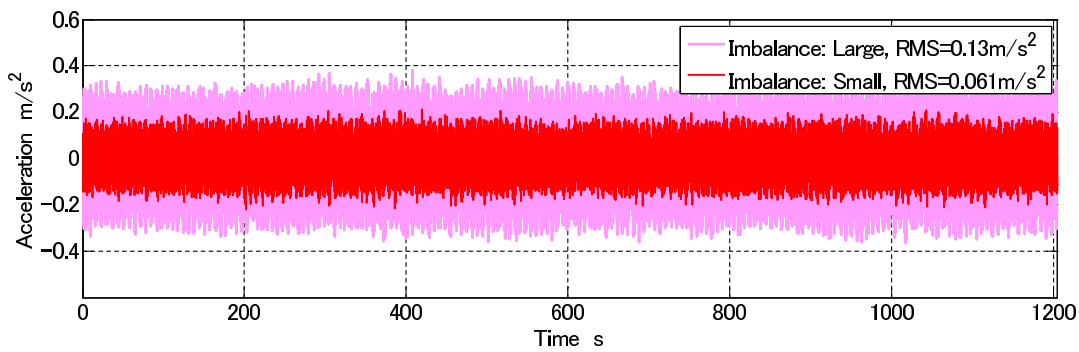

(b) Longitudinal acceleration.

Fig. 12 Time series of acceleration measured at the center of the floor. (Effect of imbalance magnitude. Normal rubber bushes were applied.)

determined to match the natural frequency of one of the major modes of the carbody bending vibration by preliminary excitation test.

Figure 12 shows the time series of vertical and longitudinal accelerations as measured at the center of floor when the normal rubber bushes (without displacement-dependent property) were used. The light blue and pink lines represent the case of large imbalance, and blue and red lines represent the small imbalance conditions, respectively, and the numerical values shown in the legend are RMS (root mean square) value of the accelerations. A large increase of acceleration is observed as imbalance became large. This means that the excitation due to imbalanced wheelset while running on a real track of a vehicle can be successfully recreated. It should be noted that a periodical disturbance of the acceleration envelope can also be found from the figure for the vertical acceleration. This periodical disturbance is caused by a phase change of imbalance according to the phase relation measurement result ${ }^{(9)}$. This may represent the phenomenon (change of induced vibration magnitude) shown in Fig.4.

Figure 13 presents the effect on acceleration when the displacement-dependent rubber bushes were applied. The imbalance conditions were set as "Large" in Table 3 in this figure. The light blue and pink lines indicate the cases where normal rubber bushes were used, and black lines represent the case when the displacement-dependent rubber bushes were applied. The static stiffness of both two types of rubber bushes were almost identical $\left(K_{\mathrm{S}}=9.0 \times\right.$ $10^{6} \mathrm{~N} / \mathrm{m}$ ). More than $30 \%$ reduction in RMS values of acceleration is observable for both vertical and longitudinal accelerations. The validity of the displacement-dependent rubber bush to suppress the excitation of the carbody due to the imbalance of wheelsets is confirmed from this figure. 


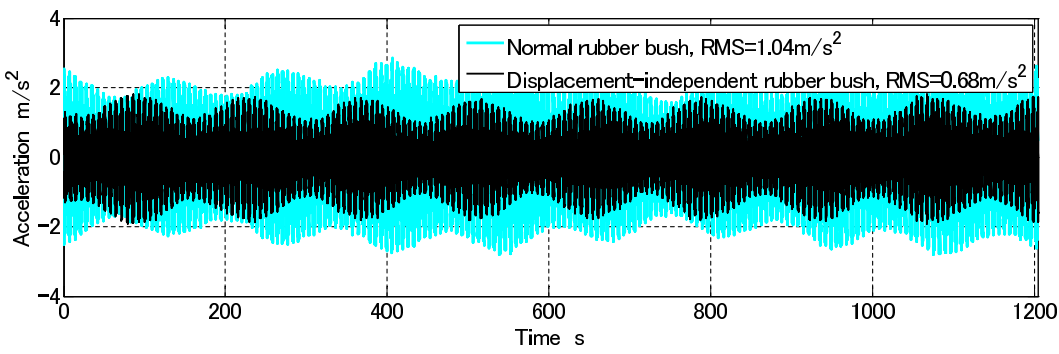

(a) Vertical acceleration.

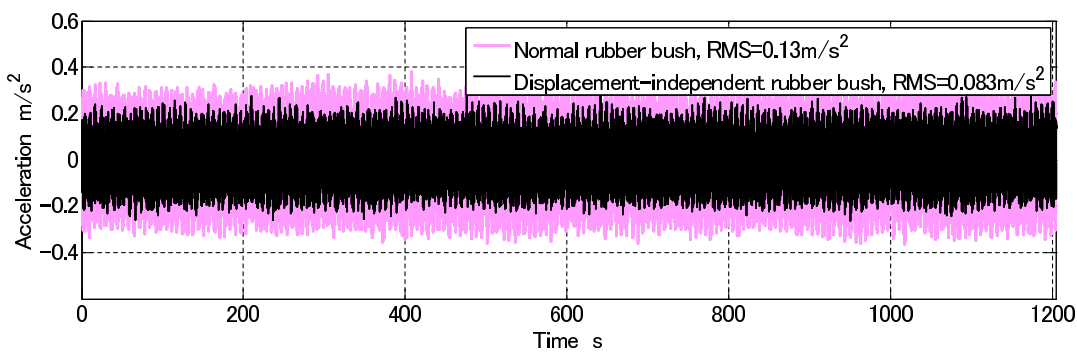

(b) Longitudinal acceleration.

Fig. 13 Time series of acceleration measured at the center of the floor. (Effect of the displacement-dependent rubber bush. Imbalance conditions were set as Large.)

\section{Conclusions}

The carbody vibration of railway vehicle induced by the rotation of mass imbalanced wheelsets has been discussed in this paper.

Some acceleration PSDs of a vehicle measured while running were presented to show the real situation when a certain amount of imbalances existed in the wheelsets. It has shown that carbody vibration become obviously large as the rotation frequency coincides with natural frequency of the carbody vibration.

To suppress the carbody excitation caused by the rotation of imbalanced wheelsets, the authors proposed a displacement-dependent rubber bush. The rubber bush has a small gap between rubber and inner fixture, and it provides the displacement-dependent property in the rubber bush stiffness. The transmission of excitation force with high-frequency and small displacement are isolated by the gap. This gap can be created simply just skipping their bonding process, so it is very simple and cost-effective countermeasure against the carbody excitation. The stiffness property can be tailored to meet the requirements from motional properties of bogie by using the FEA. We verified the effectiveness and validity of the rubber bushes applied for traction links by numerical calculation and excitation test using a full-scale test vehicle at the rolling stock testing plant.

As a next step toward a practical application for traction links, the authors are now under verifying the endurance and the effect on the stability of bogie motions of the displacementdependent rubber bushes. Furthermore, we are conducting a series of running tests on a commercial line to confirm the effectiveness under actual service conditions.

\section{Appendix. Mass Imbalance Due to Eccentricity}

If a certain amount of eccentricity $\varepsilon$ exists in a wheel or a wheelset, this causes mass imbalance directly and the excitation force generated by the rotation of such a wheelset is shown in Eq. (2). One possible reason to induce eccentricity can be supposed as small misalignment of rotational center during wheel turning (re-grinding or re-facing of wheel to correct wheel out-of-roundness or wheel flat).

In the turning work, although several methods exist actually, a wheelset is held at both end of its axle by some kind of holding jig in many cases and forced to rotate during the work. On the other hand, when a railway vehicle runs, each wheelset rotates around the center 
of each axle held by bearings at both sides. So if the rotational center during wheel turning work differs from that of wheelset axle, the difference yields eccentricity of the wheelset. One specific aspect of this type eccentricity is that the imbalance may disappear by making wheel turning work again.

A roundness measurement may be available to estimate the amount of the eccentricity; holding a wheelset with both axleboxes, which contain bearings, above rail and rotate the wheelset, and measure the circumferential profile using a dial gauge fixed on the ground. Figure A1 shows the schematic illustrations of the roundness measurement results. Figure A1(a) shows the case that the wheel is out-of-round. Since the out-of-round causes noise and vibration (which have much higher frequency than the excitation frequency of rotation of imbalanced wheelset), the wheel turning is usually intended to remove the out-of-roundness on the wheel. Figure A1(b) shows the case that the circumferential profile is true circle but eccentricity $\varepsilon$ exists. In this case, the measured circumferential profile (roundness error curve) becomes a sinusoidal curve with wave length $2 \pi D$, where $D$ is the diameter of the wheel, and the amplitude of the sinusoidal curve corresponds to the eccentricity $\varepsilon$. More practically, the eccentricity can be estimated by the peak-to-peak value of the sinusoidal roundness error curve $\delta$ as $\varepsilon=\delta / 2$. If the positions of max. and min. points (point $\mathrm{A}$ and $\mathrm{B}$, respectively in the figure) are closed in the both side wheels, the eccentricities become in-phase for both side wheels and the mass imbalance of the wheelset becomes large. Note these two figures express idealized cases; the actual measurement data will show the combination of both cases.

According to Eq. (2), in case both side wheels in a wheelset have in-phase eccentricity, the eccentricity which yields mass imbalance of $0.25 \mathrm{~kg} \mathrm{~m}$ can be obtained as listed in Table A1. From this table, we can see that relatively small misalignment may result considerable amount of mass imbalance.

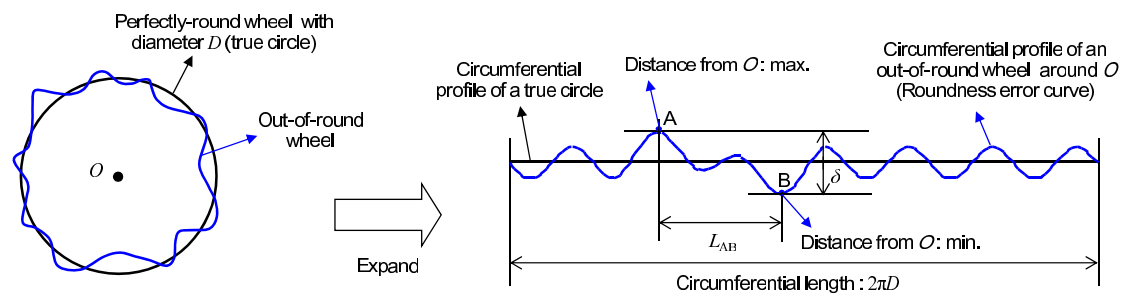

(a) Out-of-round wheel.
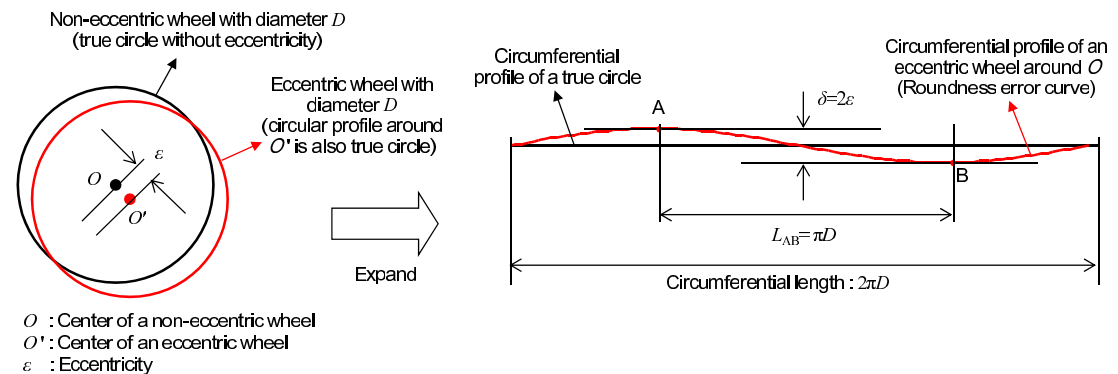

(b) Eccentric wheel.

Fig. A1 Schematic illustrations of circumferential profiles of out-of-round and eccentric wheels.

Table A1 Eccentricity which yields mass imbalance of $m_{\mathrm{w}} \varepsilon=0.25 \mathrm{~kg} \mathrm{~m}$.

\begin{tabular}{c|c}
\hline Mass of a wheelset $m_{\mathrm{w}} \mathrm{kg}$ & Eccentricity $\varepsilon \mathrm{mm}$ \\
\hline $1000 \mathrm{~kg}$ & 0.250 \\
\hline $1500 \mathrm{~kg}$ & 0.167 \\
\hline $2000 \mathrm{~kg}$ & 0.125 \\
\hline
\end{tabular}




\section{References}

( 1 ) Office for research and experiments of the international union of railways (ORE), Tests on Passenger Coaches to Determine the Maximum Permissible Out-of-balance of Wheels, Question B79 Problems Connected with the Design, Assembly and Maintenance of Trailer Stock Wheelsets, Report No.6(1967), pp.1-74.

( 2 ) Koyanagi, S., The Method of Preventing Longitudinal Vibrations of a Two-Axled Bogie Vehicle, Railway Technical Research Report (in Japanese), No.1186(1981), pp.1-31.

( 3 ) Matsui, N., Theoretical Analysis of the Railway Vehicle Vibrations Caused by the Wheelset Mass -Imbalance, Tokyu-car corp. Technical Review (in Japanese), No.36(1983), pp.2-12.

( 4 ) The Japan Society of Mechanical Engineers, Railway Vehicle Dynamics - The Latest Bogie Technologies - (in Japanese), (1996), pp.15-20, 49-51, Denkisyakenkyu-kai.

( 5 ) The Research Committee for High-speed Railway Wheelsets, Railway Wheelsets (in Japanese), (2008), pp.210-213, Maruzen Co., Ltd..

( 6 ) Takigami, T. and Tomioka T., Elastic Vibration Characteristics of Recent Light-Weight Vehicles, RTRI Report(in Japanese), Vol.16, No.3, (2002), pp.23-28.

( 7 ) Takigami, T. and Tomioka T., Modal Vibration Analysis of Recent Railway Vehicles, Proceedings of the 12th Asia-Pacific Vibration Conference, Sapporo, Japan, 6-9 August, 2007, OS12-1-1.

( 8 ) Tomioka, T., Takigami, T. and Aida, K., Modal Analysi of Railway Vehicle Carbodies Using a Linear Prediction Model, Journal of System Design and Dynamics, Vol.3, No.6(2009), pp.918-931.

( 9 ) Takigami, T., Tomioka T., Sugahara Y., Yamamoto, D. and Nishimura, T., Study on Vertical Bending Vibration of a Carbody Due to Unbalanced Mass of Wheelsets, Proceedings of the 12th Jointed Railway Technology Symposium (J-RAIL2005)(in Japanese), (2006-1), pp.229-235.

(10) Tomioka, T., Suzuki, Y. and Ueno, T., Investigation on Riding Comfort of Railway Vehicle by Changing the Specifications of Carbody, Trucks and Their Connecting Elements, Transactions of the Japan Society of Mechanical Engineers, Series C(in Japanese), Vol.66, No.645C(2000), pp.1636-1644.

(11) Tomioka, T. and Takigami, T., Reduction of Bending Vibration in Railway Vehicle Carbodies Using Carbody-Bogie Dynamic Interaction, Vehicle System Dynamics, (Accepted for publication for IAVSD 2009 supplement).

(12) Japanese Standards Association, General Requirement, JIS E 4710 : Railway Rolling Stock - Rubber Vibration Isolators - , (1995), pp.1-4. 